\title{
Karakter Perempuan Jawa Dalam Leksikon Jawa
}

\author{
M. Suryadi \\ Prodi Sastra Indonesia, Fakultas Ilmu Budaya, Universitas Diponegoro \\ mssuryadi07@gmail.com
}

\begin{abstract}
This study aims to identify the Java lexicon. The Javanese lexicon which has a relation to the character of Javanese women. The Java Lexicon which is the focus of the study is vocabulary based on the meaning of the components of the character: behavior, habits and character. Location of research in the northern coast of Central Java. Data collection methods are observation, interview (structured interview and in-depth interview), and focus grop discussion (FGD). The analytical method is the equivalent method. Using three analytical techniques: reconstruction, correlation, and context matching. The theoretical basis used is adhesion: the word-concept-referent and Sapir-Worf hypothesis. Research findings are 1) Javanese female characters are reflected in the lexicon; 2) Lexicon of Javanese female characters can be traced internally (word structure) and external (context and philosophy); 3) internal studies are analyzed diachronically and synchronously; 4) External studies are analyzed involving the components of context and cultural order that have philosophical values (micro and macro); 5) The order of word-concept-referent is a formula for reconstructing forms and meanings.
\end{abstract}

Keywords: characters, women, Javanese, lexicons.

\section{Intisari}

Penelitian ini bertujuan mengidentifikasi leksikon Jawa yang memiliki keterkaitan terhadap karakter perempuan Jawa. Leksikon yang menjadi fokus kajian adalah kosakata yang berada dalam medan makna komponen karakter: perilaku, kebiasaan, dan watak. Lokasi penelitian pesisir utara Jawa bagian Tengah. Metode pengumpulan data yang digunakan adalah observasi, interviu (structured interviewdan in-depth interview), dan focus grop discussion(FGD). Metode analisis yang digunakan adalah metode padan dibantu dengantiga piranti analisis: rekonstruksi, korelasi, dan padanan konteks. Landasan teori yang digunakan adalah daya rekat kata-konsep-referen dan hipotesis Sapir-Worf. Temuan dalam penelitian ini adalah 1) Karakter perempuan Jawa tercermin dalam leksikonnya; 2) Leksikon yang memuat konsep karakter perempuan Jawa dapat ditelusuri secara internal (struktur kata) dan eksternal (konteks dan filosofi); 3) Kajian internal dapat dilakukan secara diakronis dan sinkronis; 4) Kajian eksternal selalu melibatkan komponen-komponen konteks dan tatanan budaya yang memiliki nilai filosofis (mikro dan makro); 5) Urutan kata-konsep-referent merupakan formula untuk merekosntruksi bentuk dan makna

Kata kunci: karakter, perempuan, Jawa, leksikon. 


\section{PENDAHULUAN}

Bahasa Jawa memiliki banyak keistimewaan,selain jumlah penutur yang cukup banyak, juga memiliki cakupan wilayah yang sangat luas. Keistimewaan lainnya adalah berada dalam internal bahasa Jawa itu sendiri, yakni memiliki (1) kekayaan varian lingual, terutama pada bidang leksikon; (2) fenomena derivasi dan infleksi; (3) valensi semantic; dan (4) pola tingkat tutur. Keistimewaan internal ini menjadi salah satu faktor munculnya keragaman lingual dan keragaman dialek.

Salah satu keragaman lingual yang menjadi fokus kajian adalah keterkaitan antara bentuk-makna leksikonterhadap karakter perempuan Jawa. Bentuk keterkaitan ini memiliki keistimewaan, antara lain: keterpautan antara bentuk leksikon dengan arti semantic: harfiah, etimologi, dan filosofi. Keterpautan yang melibatkan analisis diakronis dan sinkronis. Keterpautan yang melibatkan struktur dengan konteks dan relasi hipotesis Sapir-Worf.

Adapun rumusan masalah yang diangkat dalam kajian ini adalah bagaimanamenelusuri pola varian leksikon bahasa Jawa pesisir yang terkait dengan karaketer perempuan Jawa, terutama pada leksikon bermedan makna perilaku, kebiasaan, dan watak.

Penelitian sebagai kajian yang berkesinambungan merupakan proses yang terus mengalir dari hulu sampai ke hilir. Sebuah penelitian menjadi semakin tajam dan memiliki daya guna yang sangat tinggi manakala memperlihatkan aspek temuan pada penelitian terdahulu dan penelitian segayut.Adapun rujukan yang dimanfaatkan sebagai berikut.

Kuriki et al. (2017): The modern Japanese color lexicon, penelitian ini memperlihatkan adanya persamaan antara bahasa Jepang kekinian dengan bahasa Jawa. Kedua bahasa ini memiliki persamaan walaupun dari rumpun yang berbeda. Persamaan lebih diperlihatkan pada multi gradasi pada setiap bentuk leksikon yang memiliki varian. Varian leksikon ini dapat muncul tergantung dari tingkat social dari setiap lawan bicara. Leksikon dalam bahasa Jepang selain dipengaruhi oleh tingkat social juga dipengaruhi oleh jenis maskulin dan feminine. Hasil penelitian ini 
dimanfaatkan terkait dengan pandangan bahwa setiap leksikon apa pun kategorinya memiliki pasangan yang tepat dalam setiap konteksnya, sehingga ancangan bahwa arti setiap leksikon dalam bahasa apapun tidak ada yang bersifat mutlak, yang mungkin terjadi adalah kemiripan arti atau sinonim.

Taboada, Brooke, Tofiloski, Voll, \& Stede (2011): Lexicon-Based Methods for Sentiment Analysis, Artikel ini memaparkan pertalian antara leksikon dalam teks dengan kekuatan meaning (jangkuan semantis). Jangkauan semantis dipengaruhi oleh deret leksikon yang terdapat pada entri kamus. Deret leksikon yang paling memegang peran adalah leksikon nominal. Temuan yang paling mendasar dan dimanfaatkan dalam rujukan penelitian ini adalah jangkuan meaning atau arti leksikal sangat dipengaruhi oleh leksem-leksemnya, yang tersimpan nilai positif dan atau negative. Jangkuan nilai positif sangat dipengaruhi oleh core leksikal sedang nilai negative dipengaruhi oleh rasa atau sugesti.

Gitari, Zuping, Damien, \& Long (2015): A lexicon-based approach for hate speech detection. Artikel ini mendeskripsikan bahwa leksikon dapat memiliki multi purpose, yakni untuk meyakinkan, memuji, mengejek, dan juga mengecam. Pemanfaat ini tidak dapat dilepaskan dari tujuan penuturnya dalam penyampaian peristiwa tutur. Fokus temuannya adalah leksikon dapat memiliki multi purpose baik sebagai leksikon tunggal (isolative) maupun berada di dalam tuturan (rentetan kata/kalimat). Cara pemilahannya dapat diidentifikasi dari reaksi mitra tuturnya. Kajian ini sangat membantu dalam memperkuat pandangan bahwa leksikon sebagai inti dari bahasa untuk memperjelas informasi dan amanat yang akan disampaikan oleh penuturnya.

Samsonovich \& Ascoli (2010):Principal semantic components of language and the measurement of meaning. Artikel ini memaparkan perihal matrik semantic, yakni peta kognitif pada arti semantic dari sebuah leksikon. Melalui matrik ini dapat diketahui secara detail arti sebuah leksikon. Setiap arti leksikon akan dapat diurai jangkauan semantiknya, sehingga dalam matriks tersebut akan selalu berpasangan antara komponen antonym dan sinonimnya. Artikel ini memberikan panduan dalam memilah setiap arti leksikon dalam setiap kata. Sehingga akan diperoleh kerincian setiap arti kata. Metode ini kerap kali dimanfaatkan dalam penyusunan kamus. 


\section{METODE PENELITIAN}

Lokasi penelitian berada pesisir utara Jawa bagian Tengah, Lokus penelitian difokuskan pada wilayah persebaran bahasa Jawa Pesisir: Demak, Pati, Jepara. Jenis penelitian ini adalah penelitian kualitatif, yang lebih mengandalkan fenomena lingual yang natural, dengan mempertahankan kondisi sosiokultural apa adanya, tidak ada campur tangan peneliti dalam meliu penelitian. Data ditangkap apa adanya dan diperlakukan sesuai warna dan watak data. Melalui penelitian ini diharapkan akan diperoleh kajian yang natural dan tajam sehingga tujuan yang diharapkan dapat tercapai.

Ancangan penelitian yang dimanfaatkan adalah linguistic deskriptif yang lebih memfokuskan identifikasi leksikon dan varian leksikon serta memperhatikan konsep yang diemban leksikon tersebut dan referent yang dipilih. Disamping itu, masih mempertimbangkan sosikultural masyarakat Jawa pesisir yang menyimpan nilai dan ruh kultural Jawa.

Data dalam penelitian ini meliputi data primer dan data sekunder. Data sekunder digunakan untuk mendukung data primer. Pengumpulannya dilakukan dengan menggunakan metode observasi, interviu (structured interview dan in-depth interview), dan focus grop discussion (cf. Sudaryanto, 1988).

Data dianalisis menggunakant metode padan dengan memperhatikan watak data itu sendiri. Dalam memanfaatkan metode padan dibantu dengantiga piranti analisis: rekonstruksi, korelasi, dan padanan konteks. Landasan teori yang digunakan adalah daya rekat kata-konsep-referen dan hipotesis Sapir-Worf (1929).

\section{PEMBAHASAN}

Bahasa dan budaya merupakan sebuah kepingan logam, yang tidak bisa dipisahkan. Dua sisi keping logam selalu melekat satu dengan yang lainnya, begitu juga dengan bahasa dan budaya. Manakala kajian bahasa dilakukan maka kajian budaya akan mengikutinya, sebaliknya kajian budaya diawali maka persoalan bahasa akan menyertainya. Begitu pula humannya yang mengisi ruang antara bagasa dan budaya. Tiga komponen bahasa, budaya, dan human selalu terkait dan saling mengisi: didalam bahasa akan muncul budaya dan human. Setiap bahasa apapun akan ditentukan oleh budaya dimana bahasa itu digunakan. Setiap bahasa yang digunakan ditentukan pula oleh human penggunanya.

Bahasa Jawa yang digunakan oleh masyarakat Jawa tidak dapat dilepaskan oleh 
budaya Jawa dan masyarakat Jawa itu sendiri. Kharakter bahasa Jawa selalu bertalian dengan kharakter masyarakat Jawa dan kehidupan budaya Jawa. Sebaliknya manakala mengkaji perihal karakter masyarakat Jawa dan keunikan bentuk budaya yang ada dalam masyarakat Jawa itu sendiri.

\section{Karakter Perempuan dalam Leksikon Jawa}

Karakter adalah bentuk psikologis yang melekat pada seseorang. Karakter ini menyangkut sifat, perilaku, dan kebiasaan yang secara alami melekat pada diri sesorang yang dibangun dan diwarnai oleh latar belakang sosial, budaya, dan kekuatan alam di mana seseorang itu berada. Ketiga komponen tersebut melekat secara natural dalam meliunya.

Latar belakang tidak dapat dilepaskan di mana seseorang dilahirkan dan dibesarkan sehingga karakter terus terbentuk seperti bangunan yang kait mengkait. Latar belakang sesorang ini lah yang akan membangun dan mewarnai kharakter seseorang. Latar belakang pun terkait dengan budaya di mana pranata sosial dan tatanan sosial tumbuh dan berkembang. Pranata sosial dan tatanan sosial sebagai rambu budaya di mana masyarakat berkembang selalu memiliki warna dan kekhasan sendiri: keguyuban dan kegotongroyongan salah satu bagian dari budaya itu sendiri memiliki nilai yang kuat, sekaligus sebagai ciri kebersamaan dan kerukunan.

Komponen ketiga berupa kekuatan alam. Kekuatan alam sebagai kharakter natural yang membingkai sebuah masyarakat untuk memadukan diri dengan alam, sehingga terbentuk keharmonisan antara alam dan masyarakat (manusia). Bentuk keharmonisan manusia dengan alam terciptalah bangunan-bangunan hasil budaya manausia. Salah satu bentuk keharmonisan masyarakat Jawa dengan alam adalah bentuk bangunan rumah joglo, rumah limasan, rumah palang sejajar.

Bentuk keharmonisan lain yang terkait antara latar belakang (sosial), budaya, dan kekuatan alam pada masyarakat Jawa tersimpan dalam hasil cipta manusia Jawa baik dalam bentuk fisik maupun non fisik. Bentuk fisik tercermin dalam semua aspek olah kreativitas hunian, isi dan perlengkapannya. Sedang hasil cipta non fisik tersimpan dalam pembentukan istilah kharakter perwatakan. Istilah atau sebutan kharakter perwatakan tersimpan dalam perbendaharaan kata atau leksikon bahasa Jawa, misal sebutan pada kharakter perempuan Jawa, yakni ayu, perawan, lancir, alus, kalem, isteri, semanak, grapyak, sri. 


\section{Komponen Karakter}

Karakter memiliki tiga komponen utama, yakni perilaku, kebiasaan, dan watak. Perilaku adalah kegiatan atau aktivitas manusia yang terkait dengan perbuatan untuk merangkai urutan tindakan dalam perjalanan hidup, baik yang terkait dengan diri sendiri maupun orang lain dan atau alam. Perilaku manusia dapat dikaitkan dengan tatanan sosial dimana kehidupan invidu itu berada. Dengan demikian, perilaku manusia sangat dipengaruhi oleh factor keturunan, sikap, dan norma social (cf.: Notoatmodjo, 2003).

Kebiasaan terkait dengan perbuatan sehari-hari yang selalu ada dalam kehidupan pokok atau kebutuhan hakiki manusia dalam melangsungkan kehidupannya. Kebiasaan merupakan aktivitas yang dilakukan secara berulang-ulang sehingga dapat dimungkinkan ditemukan urutan dan polanya, sehingga kebiasaan seseorang dapat dititeni 'ditengarai'.

Watak terkait dengan kondisi psikologis manusia yang sangat dipengaruhi oleh kekuatan pikiran dan rasa. Seringkali watak disejajarkan dengan tabiat. Manakala disejajarkan dengan tabiat maka watak cenderung sebagai bentuk pewarisan sifat turunan. Namun, manakala watak dikaitkan dengan kekuatan pikiran dan rasa maka watak dapat dibentuk atau dibangun sesuai kontruksi yang diharapkan.

Komponen karakter ini lah yang membangun wujud manusia seutuhnya yang diharapkan oleh orang tua (mikro) dan lingkungan (makro). Potret mikro dan makro ini dapat direkam melalui pola tutur dan pola perilaku. Pola tutur dapat dicerminkan melalui unsur-unsur bahasa, yakni leksikon, frasa, kalimat, dan wacana. Unsur-unsur bahasa ini tidak dapat dilepaskan dengan konteks yang membungkusnya.

\section{Leksikon}

Leksikon atau kosakata/perbendaharaan kata adalah unsur bahasa yang memuat informasi tentang arti kata, makna kata, dan pemakaian kata tersebut dalam bahasa yang digunakan. Dalam leksikon terdapat kumpulan kata yang dimiliki oleh sebuah bahasa. Kata yang dimiliki pun jumlahnya tak terbatas, setiap masa terus berkembang secara dinamis atau bahkan sebaliknya (luruh).

Dua komponen pokok dalam kata adalah bentuk dan makna/arti (Verhaar, 2004). Setiap kata memiliki bentuk dan arti. Mono dan poli bentuk atau pun multy arti. Sehingga dapat ditafsirkan setiap bentuk kata memeliki multi tafsir atau setiap bentuk 
kata memiliki informasi yang akan disampaikan (cf.: hipotesis sapir-worf, dalam Kay and Willett Kempton, 1984).

Leksikon yang akan dikaji terkait dengan kosakata yang memiliki arti leksikal, baik yang sesuai kamus atau harfiah/literal (arti kata sebagaimana aslinya/asalnya) maupun etimologi (asal usul suatu kata). Dimungkinkan juga dikaji berdasarkan arti etnologinya. Penelusuran kamus yang dimanfaatkan adalah kamus bahasa Jawa kuna/KBJK (Zoetmulder-Robson, 1995) dan kamus bahasa Jawa/KBJB (Sudaryanto, 1991). Unit analisis pada satuan leksikon yang bergloss kharakter perempuan Jawa.

\section{Karakter Perempuan Jawa}

Perempuan Jawa memilikilimakarakter utama dalam kedudukannya sebagai wanita Jawa, yakni ayu, lembut, kuat, empati, dan mesra. Di samping itu, potret karakter perempuan Jawa juga dipaparkan dalam Serat Centhini (1981), yakni diibaratkan seperti lima jari tangan, sebagai berikut.

1) Jempol 'ibu jari', mengandung filososfi bahwa perempuan berkedudukan sebagai istri harus pol 'total' mengabdi kepada suami.

2) Telunjuk 'jari telunjuk', mengandung filosofi bahwa perempuan sebagai istri harus mentaati perintah suami.

3) Panunggul'jari tengah' mengandung filosofi bahwa perempuan berkedudukan sebagai istri harus bangga akan keadaan suami, baik kelebihan maupun kekuarangan suami.

4) Manis 'jari manis' memiliki nilai filosofi bahwa perempuan berkedudukan sebagai istri harus selalu bersikap manis terhadap suaminya.

5) Jejenthik 'jari kelingking' memiliki nilai filosofi bahwa perempuan berkedudukan sebagai istri harus selalu berhati-hati, teliti, rajin dan terampil dalam melayani suami serta anak-anaknya.

\section{Filosofi Perempuan Jawa}

Filosofi perempuan Jawa yang terkait dengan perilaku kehidupan sebagai seorang wanita pendamping kehidupan. Wanita dalam tatanan budaya Jawa sebagai pendamping hidup dalam keluarga. Pada kehidupan keluarga perempuan memiliki warna dan bahkan mewarnai kehidupan keluarga Jawa. Peran perempuan Jawa dapat dianalogikan sebagai 
strudara dari sebuah film. Sebuah film menjadi hebat dan luar biasa peran aktornya tidak dapat dilepaskan dari peran studaranya. Begitu juga bahwa kehidupan keluarga menjadi sukses tidak dapat dilepaskan dengan peran perempuan Jawa sebagai pendamping hidup dalam kehidupan berkeluarga. Kekuatan nilai filisofi diibaratkan lima jari tangan yang siap bekerja sama sesuai dengan fungsinya masing-masing.

\section{Karakter Perempuan Jawa dalam Leksikon Jawa}

Karakter Perempuan Jawa banyak tersimpan dalam leksikon Jawa. Setiap kata atau leksikon dalam bahasa Jawa memiliki arti semantik yang sangat kuat. Arti semantik yang tersimpan tidak hanya memiliki arti yang literal saja namun juga memiliki etimologi yang mengandung nilai filosofis. Beberapa leksikon Jawa yang terkait dengan karakter perempuan Jawa dideskripsikan pada kajian berikut ini.

\section{Leksikon Wadon}

Leksikon wadon 'perempuan' secara diakronis dirunut berasal dari bahasa Jawa Kuna wadon atau wadwa 'perempuan' (KBJK: 1364-1365) atau wadhu 'temanten perempuan, isteri muda'. Di samping itu, leksikon wadhu juga memiliki arti abdi atau mengabdi, yakni mengabdi kepada suami dalam kehidupan berumah tangga. Adapun ungkapan Jawa yang memuat leksikon wadon, yakni:

(1) Wadon iku stri kang utama ana ning keluarga

'Perempuan itu ibu yang baik dalam tatanan kehidupan keluarga'

(2) Tiyang wadon utama ana ning nanah

'Perempuan keutamaannya ada di dalam hatinya.

\section{Leksikon Wanita}

Leksikon wanita secara diakronis ditemukan dalam kamus Jawa Kuna wanita (KBJK: 1383) yang memiliki arti 'perempuan, wanita, dan isteri'. Di samping itu, terdapat pula menafsirkan bahwa leksikon wanita sebagai bentuk akronim dari dua kata wani-ta(ta), yakni wani dan tata. Leksikon BJ: wani 'berani' dan leksikon BJ tata 'teratur'.

Leksikon BJ: wanita memiliki dua pengertian yang paradoks, yakni seorang wanita Jawa sepatutnya sebagai seorang insan yang mau ditata atau diatur agar kehidupan rumah tangganya menjadi lebih nyaman dan bahagia. Pengertian lain, memiliki arti yang berseberangan, namun memiliki tujuan yang sama, yakni mencapai 
keluarga yang nyaman dan bahagia. Adapun arti kedua adalah wanita Jawa harus memiliki kemampuan untuk menata rumah tangga, sehigga muncul aora penataan kehidupan rumah tangga yang rapi dan teratur.

Ungkapan Jawa yang berisi leksikon wanita, sebagai berikut.

(1) Wanita sing isa ngademke rasa

'Perempuan yang bisa menentramkan jiwa'.

(2) Wanita utama ana ning ngendika

'Perempuan yang paling utama ada di dalam ucapannya'

\section{Leksikon Estri}

Leksikon estri ditemukan dalam kamus bahasa Jawa Kuna: istri, estri'isteri’ (hal 399) dan stri 'perempuan' (KBJK: 1126). Selain itu, dalam bahasa Kawi: estren 'pendorong/penyurung'.

Merunut dari bahasa Kawi bahwa leksikon estri 'wanita' secara diakronis memiliki arti pendorong atau motivator bagi sang suami agar lebih memiliki power dalam kehidupan berumah tangga. Nilai filosofis yang disampaikan adalah estri yang hebat harus dapat menjadi sutradara yang ulung agar skenario kehidupan rumah tangga yang diperankan oleh sang suami dapat sukses untuk meraih cita-cita dalam kehidupan rumah tangga.

Adapun leksikon Jawa estri ditemukan pada ungkapan berikut ini.

(1) Pilihen estri kang gemati, urepmu bakal diberkati.

'Pilihlah perempuan yang mengerti/setiti, kehidupan rumah tanggamu akan harmoni'

(2) Stri saktemen sisihane ati

'Isteri itu sebanarnya belahan hati'

\section{Leksikon Putri}

Leksikon putrisecara diakronis ditemukan dalam bahasa Jawa Kuna putri 'putri, anak perempuan' (KBJK: 893). Ada anggapan bahwa leksikon putri ‘putri' sebagai akronim dari klausa pupus sekotri perkawis. Klausa ini memiliki arti pupus(telah putus) seka (terhadap) tri (tiga) perkawis (persoalan atau kewajiban). Tiga persoalan tersebut adalah, 
1) Pupus terhadap persoalan pengabdian disejajarkan dengan arti wadon.

2) Pupus terhadap persoalan penataan disejajarkan dengan arti wanita.

3)Pupus terhadap persoalan pendorong/penyemangat/motivator disejajarkan dengan arti estri.

Dengan demikain, leksikon putri adalah perempuan Jawa yang belum dikenai beban atau tanggung Jawab dalam kehidupan berumah tangga (dinukil dari nasehat Ki Sutrima, 2018). Adapun leksikon putri ditemukan pada ungkapan Jawa berikut ini.

(1) Putri sing iso natani ati kuwi wong sing duwe ilmu

'Perempuan yang bisa menata hati itu perempuan yang memiliki pengetahuan'

(2) Putri agung kuwi lembut ing pitutur.

'Perempuan berderajat / terpelajar itu bijaksana dalam nasehat'

\section{Leksikon ayu 'cantik'}

Leksikon ауи secara diakronis ditemukan dalam bahasa Jawa Kuna hayu memiliki arti 'kebaikan, kecantikan, kemolekan'(KBJK: 346). Leksikon ayu/hayu memiliki arti yang komprehensif, yakni kecantikan hati, kemolekan paras, dan kebaikan perilaku. Dengan demikian, nilai filosofis hayu atau ауu adalah kecantikan menyeluruh, yakni tidak saja cantik fisik atau visual namun juga cantik perilaku, tabiat, dan tindak tanduk.

Kecantikan perempuan Jawa sebagai simbul keteduhan dan kasih sayang seorang wanita, sebagai ibu rumah tangga. Ukuran cantik perempuan Jawa adalah cantik batiniah daripada cantik lahiriah. Parameter cantik terletak pada kepandaian perempuan Jawa memberikan warna keharmonisan dalam rumah tangga. Seorang anak menjadi terlindung bila dekat dengan ibunya. Seorang suami menjadi nyaman bila berdampingan dengan isterinya.Leksikonayu kerapkali ditemukan dalam ungkapan berikut.

(1) Ayu sing sejati ana ning jerone wong wadon sing iso ngormati bojone 'Cantik yang sebenarnya berada pada isteri yang menghormati suaminya'

(2) Pilihen sing ayu jobo jero

'Pilihlah perempuan yang cantik lahir dan batin' 


\section{Leksikon Gapyak}

Leksikon gapyak ditemukan dalam kamus bahasa Jawa baru gapyak yang memiliki arti ramah (KBJB: 257). Leksikon gapyak mengandung nilai pesan bahwa perempuan Jawa memilki keluwesan dalam bergaul, kepiawaian dalam mediasi, narator, dan riang dalam menghadapi persoalan.

Leksikon gapyak 'ramah' memiliki arti positif, yakni mudah menyapa kepada mitra, mudah memaafkan, dan harmoni dalam pergaulan. Sehingga perempuan Jawa kerapkali diibaratkan sebagai perhiasan rumah tangga. Setiap yang dituturkan perempuan Jawa dalam kehidupan rumah tangga selalu menjadi awal kebahagiaan dan keteduhan dalam kehidupan berumah tangga. Leksikon grapyak ditemukan pada data kalimat berikut.

(1) Sing gapyak cedak kara sanak.

'Perempuan yang murah senyum dekat dengan saudara/keluarga'

(2) Gapyak sing ngepenake ati.

'Ucapan ramah sanagat menyejukan hati'

\section{Leksikon Ngalah}

Leksikon ngalah atau kalah ditemukan dalam bahasa Jawa Kuna: kalah 'mengalah' (KBJK: 440) dan kamus bahasa Jawa baru (KBJB: 127). Leksikon ngalah 'mengalah' dalam kehidupan masyarakat Jawa memuat amanat yang positif. Adapun amanat yang disampaikan adalah mengalah untuk menghindari konflik, namun untuk menjaga keharmonisan sosial.

Leksikon ngalah dalam filosofi Jawa adalah meraih kemenangan tanpa melukai lawannya. Ungkapan Jawa muncul kalah ning menang 'kalah tapi menang'. Karakter ngalah dimiliki oleh perempuan Jawa, yakni mampu memposisikan diri dalam kehidupan rumah tangga, untuk menggapai kehidupan rumah tangga yang sukses. Pada kehidupan Jawabahwa dibalik rumah tangga sukses terdapat estri/perempuan yang tangguh.Adapun leksikon ngalah ditemukan dalam ungkapan Jawa, sebagai berikut.

(1) Ngalah sitik entuk bathi sak gephuk.

'Perbuatan mengalah untuk meraih kemenangan'

(2) Ngalah ora banjur kala.

'Mengalah bukan berarti mengalah' 


\section{SIMPULAN}

Hasil analisis kajian "Karakter Perempuan Jawa dalam Leksikon Jawa” mengungkap keterikatan antara leksikon-konsep-referent dalam filosofi budaya Jawa tentang karakter perempuan.

Temuan kajian ini adalah 1) Karakter perempuan Jawa tercermin dalam leksikonnya; 2) Leksikon yang memuat konsep karakter perempuan Jawa dapat ditelusuri secara internal (struktur kata) dan eksternal (konteks dan filosofi); 3) Kajian internal dapat dilakukan secara diakronis dan sinkronis; 4) Kajian eksternal selalu melibatkan komponen-komponen konteks dan tatanan budaya yang memiliki nilai filosofis (mikro dan makro); 5) Urutan kata-konsep-referent merupakan formula untuk merekosntruksi bentuk dan makna.

\section{Daftar Pustaka}

Gitari, N. D., Zuping, Z., Damien, H., \& Long, J. 2015. A lexicon-based approach for hate speech detection. International Journal of Multimedia and Ubiquitous Engineering, 10(4), 215-230. https://doi.org/10.14257/ijmue. 2015.10.4.21

Kay, Paul and Willett Kempton. 1984. "What is the Sapir-Whorfhypothesis?"American Anthropologist 86, 65-79.

Kuriki, I., Lange, R., Muto, Y., Brown, A. M., Fukuda, K., Tokunaga, R., Shioiri, S. 2017. The modern Japanese color lexicon. Journal of Vision, 17(3), 1. https://doi.org/10.1167/17.3.1

Notoatmodjo, Soekidjo. 2003. Pendidikan dan Perilaku Kesehatan. Rineka Cipta. Jakarta.

Samsonovich, A. V., \& Ascoli, G. A. (2010). Principal semantic components of language and the measurement of meaning. PLoS ONE, 5(6). https://doi.org/10.1371/journal.pone.0010921

Sudaryanto. 1988. Metode dan Aneka Teknik Analisis Bahasa. Yogyakarta: Duta Wacana University Press. 1991. Kamus Indonesia-Jawa. Yogyakarta: Data Wacana University Press.

Sumahatmaka, R.M.A.1981. Ringkasan Centini (Suluk Tambanglaras), PN Balai Pustaka, Cetakan pertama.

Taboada, M., Brooke, J., Tofiloski, M., Voll, K., \& Stede, M. (2011). Lexicon-Based Methods for Sentiment Analysis. Computational Linguistics, 37(2), 267-307. https://doi.org/10.1162/COLI_a_00049 
Verhaar, J.W.M. 2004. Azas-asas Linguistik Umum. Yogyakarta: Gadjah Mada University Press.

Zoetmulder, P.J. dan S.O.Robson. 1995. Kamus Jawa Kuna-Indonesia. Jakarta: PT Gramedia Pustaka Utama 